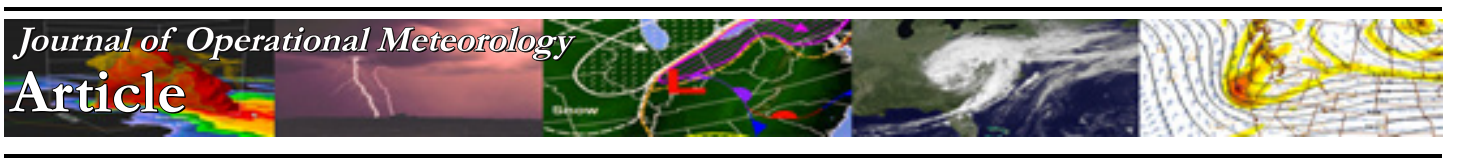

\title{
Development and Evaluation of the GLM Stoplight Product for Lightning Safety
}

\author{
GEOFFREY T. STANO \\ ENSCO, Inc./NASA Short-term Prediction Research and Transition Center (SPoRT), Huntsville, Alabama
}

MATTHEW R. SMITH

The University of Alabama in Huntsville/NASA Short-term Prediction Research and Transition Center (SPoRT), Huntsville, Alabama

CHRISTOPHER J. SCHULTZ

Earth Science Branch/NASA Short-term Prediction Research and Transition Center (SPoRT), NASA Marshall Spaceflight Center, Huntsville, Alabama

(Manuscript received 8 June 2018; review completed 19 April 2019)

\begin{abstract}
The launch of the Geostationary Lightning Mapper (GLM) aboard Geostationary Operational Environmental Satellite-R/S (GOES-16/17), provides new opportunities to support lightning safety, such as the 30-min hazard ("stoplight") safety product developed by the National Aeronautics and Space Administration's Short-term Prediction Research and Transition Center. This product plots the spatial extent where lightning occurred over the past 30 min and color codes the data in 10-min bins. Using GLM's mapping of the spatial footprint of individual flashes, the product identifies when temporal rules for lightning safety have been met based on the needs of decision-support partners [commercial airlines, $10 \mathrm{~min}$; United States Air Force (USAF) 45th Weather Squadron, $20 \mathrm{~min}$; emergency management (EMA)/National Weather Service (NWS), $30 \mathrm{~min}]$. The effort was guided by EMA partners requesting a product that quickly shows the location and age of lightning observations in an easy-to-interpret visualization. Analysis of lightning safety rules of thumb were performed in the framework of the GLM stoplight product to determine the number of times each of the partner criteria would be violated using an Eulerian-based approach simulating an integrated decision support point of view. The temporal criteria for commercial airlines, USAF, and EMA/NWS were violated $9.5 \%, 3.5 \%$, and $1.4 \%$ of the time within this sample, respectively. Examples are provided to show the GLM 30-min hazard product in linear convection, multicellular convection, and electrified snowfall events. Illustrations also demonstrate how this GLM safety product and ground-based, lightning-location systems can work in tandem to maximize lightning safety protocols.
\end{abstract}

\section{Introduction}

Lightning remains one of the leading causes for weather related-fatalities in the United States (López et al. 1993; Curran et al. 2000; Holle 2016a). Statistics for fatalities and injuries are likely underrepresented due to several factors including availability of information (López et al. 1993), many lightning casualty events involving only one person, or with lightning being listed as a secondary, rather than primary, cause of death or injury by the medical system (Mogil et al.
1977; López and Holle 1998). Furthermore, Cherington et al. (1999) stated that in the state of Colorado there are generally 10 lightning-related injuries requiring medical treatment per lightning fatality. Holle (2016b) expanded on the Cherington et al. (1999) findings and stated that the 10:1 ratio of injuries to deaths applies in other developed countries where lightning-safe locations are readily available.

In the United States, lightning fatalities have decreased from over 400 deaths per year in the early 20 th century to less than 30 deaths annually more recently 
(López and Holle 1998; Curran et al. 2000; Holle et al. 2005; Jensenius 2014). Additional information can be found at www.weather.gov/safety/lightning-safety. According to López and Holle (1998), the lightning fatality rate has decreased from nearly 6 fatalities per million people per year to 0.1 fatalities per million people per year. This trend has been achieved, even as the United States' population has quadrupled, due to improvements in structures and fully enclosed, metaltopped vehicles (Holle 2012); a more urban population; and changes in outdoor activities such as recreation and agricultural work (Holle et al. 2005; Jensenius 2014). Also, expanded efforts in lightning education and awareness have been ongoing for over a decade now in the United States (Cooper and Holle 2012; Jensenius and Franklin 2014).

As Holle (2016a) shows, lightning fatalities have shifted from agricultural and indoor settings to recreational and non-agricultural outdoor incidents as of 2014-2015. Figure 1, adapted from the National Oceanic and Atmospheric Administration (NOAA, 2019), provides a visual representation of the time periods where the lightning threat is greatest versus an individual's greatest exposure to the lightning risk. Additionally, based on reports, many lightning victims were attempting to reach safety or were near a safe location when struck (Jensenius 2019).

The issues listed demonstrate that lightning remains a serious threat even with the strides made in lightning safety. Local emergency managers, often in conjunction with their partner National Weather Service (NWS) offices, continue to develop new ways to alert individuals and organizers of large outdoor events to the threat of lightning. The National Aeronautics and Space Administration's (NASA's) Short-term Prediction Research and Transition Center (SPoRT; Darden et al. 2002; Goodman et al. 2004; Jedlovec 2013; Berndt et al. 2017) has partnered with three Tennessee county emergency management (EMA) offices (Bedford, Coffee, and Hamilton) and the Marshall Space Flight Center (MFSC) in Huntsville, Alabama to help integrate the new Geostationary Lightning Mapper (GLM; Goodman et al. 2013) observations into their lightning safety operations. These users have indicated that a useful tool requires several features. These include 1) quickly identifying where lightning is located, 2) identifying the time since the last occurrence of lightning, and 3) being accessible on mobile devices. The GLM observations have been selected as the data set of choice because they have a near-hemispheric

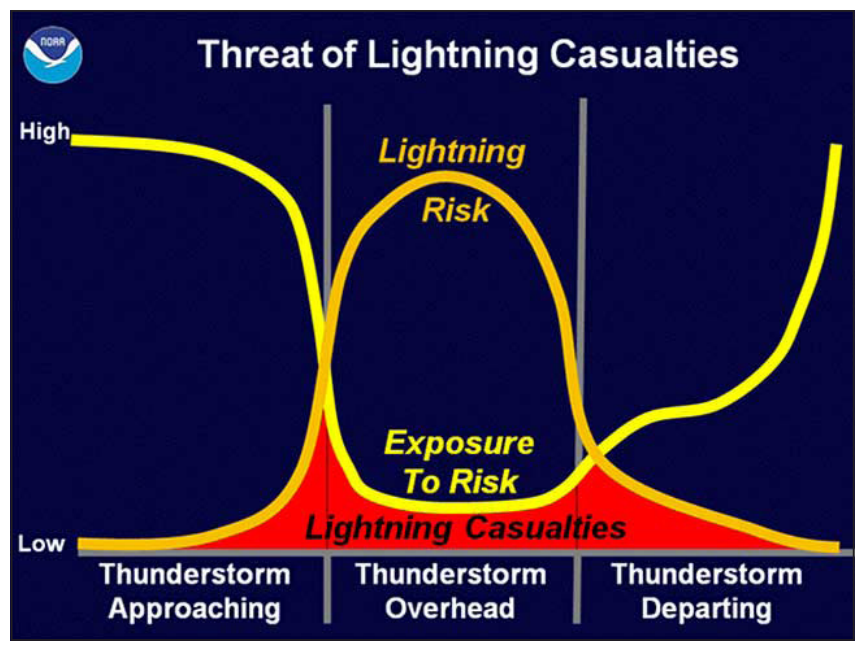

Figure 1. The threat of lightning versus the exposure to risk is inversely proportional (www.weather.gov/safety/ lightning-safety-overview). In other words, individuals typically seek shelter to avoid the rain. However, many individuals are struck by lightning as thunderstorms approach or depart a region, often when there is little or no associated rainfall. Click image for an external version; this applies to all figures hereafter.

field of view, can observe total (i.e., cloud-to-ground and intra-cloud) lightning, and observe spatial extent. Also, GLM observations are not proprietary and can be shown publicly in real-time.

Work by the SPoRT team in Schultz et al. (2017, 2018) shows that total lightning from lightning mapping arrays (LMA; Rison et al. 1999) provide additional lead time for lightning safety decision support. This increased lead time is due to the spatial information that total lightning measurements from LMA or GLM have versus traditional ground-based networks such as the National Lightning Detection Network (NLDN) or Earth Networks Total Lightning Network (ENTLN). Schultz et al. (2017, 2018) also found an increase in operational downtime (i.e., work stoppages) using the LMA data versus NLDN observations. Schultz et al. $(2017,2018)$ also states that further work is needed to properly assess how the risk assessment changes with spatial-extent observations. This paper describes the GLM 30-min hazard, or "stoplight," safety product developed by NASA SPoRT (first shown in Schultz et al. 2017) and its validation relative to current lightningsafety metrics used to inform industry and the public about cessation of the lightning threat at a specific location. Also, use within MFSC EMA procedures is discussed to provide feedback on how using total 
lightning information from GLM for outdoor work cessation has altered their policies.

\section{Data and methods}

\section{a. The Geostationary Lightning Mapper (GLM)}

The data used in the NASA SPoRT GLM stoplight safety product for this paper are from GLM during the GOES-R validation campaign in 2017 (Goodman et al. 2017; Rudlosky et al. 2017). The GLM detects lightning in a narrow wavelength at $777.4 \mathrm{~nm}$ that serves as an atmospheric window for light escaping cloud tops from lightning detected during both night and day (Christian and Goodman 1987; Christian et al. 1992; 2006; Goodman et al. 2013). The GLM field of view is nearly hemispheric, ranging from $54^{\circ}$ north and south. The GLM observations will be available from the Pacific to Atlantic basins and most of North and South America with GOES-16 and -17 (Goodman et al. 2013).

A brief summary of Goodman et al. (2013) is provided here to explain the basic observations provided by the GLM. The base observation of the GLM is an event. This is any detection of light above a background threshold by a GLM charge-couple device pixel. The GLM checks this every $2 \mathrm{~ms}$. From there, events can be clustered in time and space into groups, where the group centroid location is weighted based on the optical power of the associated events. A GLM group represents a single optical pulse often associated with return stroke and $\mathrm{k}$ change processes in the cloud (Goodman et al. 1988; Christian et al. 2000; Bitzer and Burchfield 2016; Bitzer 2017). Optical pulses can span multiple GLM pixels, which vary in size from 8-14 $\mathrm{km}$, based on the distance from nadir. For most of the figures in this paper, a GLM pixel size of $10 \mathrm{~km}$ was used. The group designation mitigates the splitting of a single optical pulse across GLM pixels. Subsequently, the groups can be clustered in time and space to form flashes whose centroid location is based on the optical power of all the associated events that make up the groups that comprise the flash. This will not always have a direct one-to-one comparison with ground networks (i.e., ENTLN and NLDN), as the GLM and the ground networks inherently observe lightning at different points within the life cycle of the lightning flash. The GLM also includes optical intensity data. The GLM data are then sent as a netCDF file over the GOES Rebroadcast (GRB) with $20.5 \mathrm{~s}$ of data having a latency of no more than $16 \mathrm{~s}$. NASA SPoRT receives
GLM data in real-time from GRB antennae located at the MFSC in Huntsville, Alabama.

\section{b. The GLM stoplight safety product}

The GLM stoplight safety product displays where lightning is occurring and where it has been. This provides a visual representation of lightning safety metrics for end users (e.g., aviation, emergency managers, etc.). Each GLM pixel that has been illuminated within a $30-\mathrm{min}$ period is retained, and each pixel is color-coded based on the age of the last illumination.

The initial stoplight product, as described here, used an early sample of reprocessed GLM data. Approximately $80 \mathrm{~h}$ of data from 11 separate days in 2017 were available (Table 1). These data have been corrected by the GLM validation and GLM science teams as part of the GOES-16 GLM validation field campaign (Rudlosky et al. 2017). The corrections focused on removing spurious false observations and geolocation errors. These data were processed to identify the time gap between any two GLM events observed in each GLM pixel. An Eulerian approach was taken to focus on individual locations. Additionally, this allowed an analysis without needing to identify individual storms. Lastly, although GLM events were used to calculate the time differences, most displays in this article use GLM groups due to easier plotting with these early GLM data. Future work for the stoplight will be plotted with GLM events, which will provide a superior sense of the spatial extent of lightning. For an example of how GLM events, groups, and flashes combine, see Goodman et al. (2013) Fig. 5.

There were 218 million GLM event-pair time differences in this dataset (i.e., where time differences between two consecutive GLM events in the same pixel were calculated). The vast majority of these GLM event-pair time differences were fractions of a second, indicating intra-flash time periods (Goodman et al. 2013). For this analysis, only inter-flash times are needed. A minimum difference of 1 min was used to ensure looking at two distinct flashes in the pixel. Certainly, flash rates can exceed one flash per minute, and inter-flash times of less than a minute exist. From our safety perspective, an end user will not reset the clock after every flash but monitor conditions on a minute-to-minute basis. For comparison, the minimum time to wait after a flash with no subsequent flashes in order to resume operations is $10 \mathrm{~min}$, as used by 
Table 1. Dates and available times of the reprocessed GLM data used in this contribution. In total 4,763 min $(\sim 79.4$ h) of data over the entire GLM field of view were available.

\begin{tabular}{|c|c|c|}
\hline Start Time - UTC (Date) & End Time - UTC (Date) & Total Time Available (min) \\
\hline 1844 (21 March 2017) & 0122 (22 March 2017) & 398 \\
\hline 0631 (16 April 2017) & 1417 (16 April 2017) & 466 \\
\hline 1657 (18 April 2017) & 2308 (18 April 2017) & 391 \\
\hline 2139 (20 April 2017) & 0441 (21 April 2017) & 422 \\
\hline 1928 (22 April 2017) & 0120 (23 April 2017) & 352 \\
\hline 0627 (27 April 2017) & 1143 (27 April 2017) & 316 \\
\hline 0300 (29 April 2017) & 1054 (29 April 2017) & 474 \\
\hline 1857 (8 May 2017) & 0358 (9 May 2017) & 541 \\
\hline 1308 (12 May 2017) & 2050 (12 May 2017) & 462 \\
\hline 1119 (14 May 2017) & 1909 (14 May 2017) & 470 \\
\hline 0200 (17 May 2017) & 0951 (17 May 2017) & 471 \\
\hline
\end{tabular}

the Federal Aviation Administration (FAA; Miller and Demetriades, 2018).

The upper bound of our time differences was 45 min. Capturing cases where the time interval exceeds 30 $\mathrm{min}$ is critical as there remains a non-zero probability of lightning to still occur after this time interval. This upper bound was selected arbitrarily, although it reasonably represents the convective lifecycle of an ordinary thunderstorm (e.g., Dye et al. 1986; Bringi et al. 1997) from a single reference point. This upper bound allows for $15 \mathrm{~min}$ of time for electrification beyond the base 30-min threshold. Additionally, limiting the upper bound to 45 min minimizes the effect of multiple storms impacting the same GLM pixel location over several hours. This is imperfect but provides a general view for this first effort. Using the 1-45-min time-difference range (i.e., inter-flash intervals) condenses our dataset from 218 million to 7427354 time-differences to analyze.

A $10 \times 10 \mathrm{~km}$ grid was created to generate the GLM stoplight safety product. This used a simpler, demonstration resolution, as the actual GLM resolution varies from 8-14 km from nadir to the edge of the field of view. Later versions will fully address this change in resolution. Additionally, the $10-\mathrm{km}$ resolution is the approximate size of an airport buffer for lightning safety (Holle et al. 2016). This early demonstration method does not account for changing pixel size of GLM away from nadir, but the product will be updated to account for this in the future. The elapsed time since the last GLM event detection is stored in each grid box. If the elapsed time was within 0-9 min, it was colored red, 10-19 min was colored yellow, and 20-29 min was colored green (hence the origin of the "stoplight" term). However, end users have recommended not using green in subsequent versions of the product to avoid incorrect assumptions that green means safe. Any times that exceed $30 \mathrm{~min}$ were set to the background color of the map (i.e., the data were dropped from the product for being too old). This 30 -min threshold was selected to coincide with the 30-min lightning safety rule of thumb that advises that individuals should remain indoors for 30 min after hearing thunder or seeing a lightning flash (www.weather.gov/safety/lightning-tips). The color scale allows accommodation of the needs of operational decision makers who use smaller time windows (e.g., aviation; Holle et al. 2016). Figure 2 is a prototype example of the stoplight safety product over Texas and Louisiana. Lastly, color-coding lightning data by time is not new, but the stoplight product is the first to incorporate spatial extent information.

\section{c. GLM stoplight safety validation}

This analysis approaches validation from the standpoint of a person performing decision support. Because of how the GLM instrument assigns the location of lightning at the most basic level, each GLM pixel is treated as if there is a decision maker at the center of the pixel who only cares about decisions within that GLM pixel. This approach is different from other lightning initiation and cessation studies that have either followed a particular storm (e.g., Stano et al. 2010) or examined lightning within an area (e.g., MacGorman 
et al. 2011). Schultz et al. (2017) demonstrated that an Eulerian approach of examining these data from an end-user standpoint provided extra lead time on the first cloud-to-ground strike. Therefore, this study will use each GLM pixel as a decision point to simulate how decision-support partners would view these data for local area decisions or other areas of interest (e.g., a ball field, stadium, or amphitheater).

Next, details were determined for when the time interval between two lightning flashes would exceed the 10-, 20-, and 30-min safety criteria used for lightning safety by end users. This provides a method by which the authors can provide metrics on the likelihood that a new flash will occur over their location using different safety criteria of different operational end users. Given this, our analysis is concerned with time intervals that exceed the various lightning safety criteria of end uses. The minimum wait time is from commercial aviation, which uses 10 min since the last flash to resume activities on an aircraft ramp (Miller and Demetriades, 2018). Twenty minutes represents known USAF "resume times" for Patrick Air Force Base, although this has been revised recently down to 15 min (W. P. Roeder, personal communication). Thirty minutes represents the amount of time for resuming outdoor activities for EMA and NWS partners. These times are general rules of thumb and can be extended based on current conditions.

\section{Analysis}

a. Preliminary assessment of GLM observations used in conjunction with the "30 min after the last lightning flash” guidance

Lightning cessation is a critical component of lightning safety. Despite its importance, it is a difficult parameter to quantify with limited, available literature (Stano et al. 2010; Schultz et al. 2013; Preston and Fuelberg 2015; Holden et al. 2018). Although the stoplight product does not directly address lightning cessation, it can support lightning safety by monitoring when lightning has occurred at a given location.

As discussed in Section 2b, the GLM dataset was condensed from 218 million time-difference pairs to approximately 7.4 million. This reduced selection came from removing any time difference of less than $1 \mathrm{~min}$ in order to assure that any time differences analyzed came from two distinct flashes. With these 7.4 million cases, the average time difference was $264 \mathrm{~s}(4.4 \mathrm{~min})$ with a

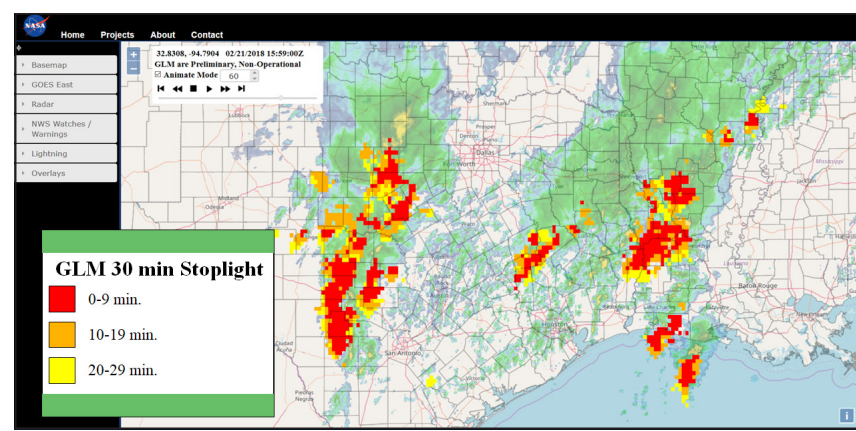

Figure 2. Prototype web mapping server tool that allows end users to combine multiple data sets on one display. This example, over TX and LA, displays the GLM stoplight safety product from 1530-1539 UTC on 21 February 2018 (note the 10-19- and 20-29-min colors reflect the updated color curve as recommended in Section 2b), radar reflectivity at 1556 UTC, as well as the requested geopolitical boundaries and roads.

median value of $137 \mathrm{~s}(2.3 \mathrm{~min})$. The 75 th percentile was $265 \mathrm{~s}$ (4.4 $\mathrm{min})$, the 95th percentile was $965 \mathrm{~s}$ (16.1 $\mathrm{min}$ ), and the 99th percentile was $2008 \mathrm{~s}$ (33.5 min). Next, the 7.4 million pair samples were applied to the 2017 FAA, USAF 45th Weather Squadron, and general public guidance for lightning safety. Each criterion requires a temporal window without lightning of 10 , 20 , and $30 \mathrm{~min}$, respectively, before declaring it safe to resume outdoor operations.

We consider the breakdown of how often each time interval (e.g., 10, 20, and $30 \mathrm{~min}$ ) is exceeded and include 40 min to capture extreme delays (Fig. 3). Within the 7.4 million inter-flash pairs, there were 708 919 cases $(9.5 \%)$ that exceeded $10 \mathrm{~min}$. Another 3.5\% (262 264 cases) exceeded $20 \mathrm{~min}$, whereas $1.4 \%$ of the cases (107 018) exceeded 30 min. Lastly, 27332 cases $(0.4 \%)$ had a time-interval difference greater than 40 min. The 80-h analysis of GLM data indicates that the 30-min guidance is reasonable for lightning safety, but a non-zero potential for lightning occurring afterwards remains.

b. Importance of spatial extent and intra-cloud observations

An example demonstrating the GLM's ability to identify spatial extent comes from 22 October 2017 (Figs. 4 and 5). Figure 4 shows the GLM event density at 1235 UTC as part of a line of storms extending from central Texas into Louisiana. At this time, lightning was primarily confined to the convective regions of the line of storms. However, 2 min later at 1237 UTC (Fig. 


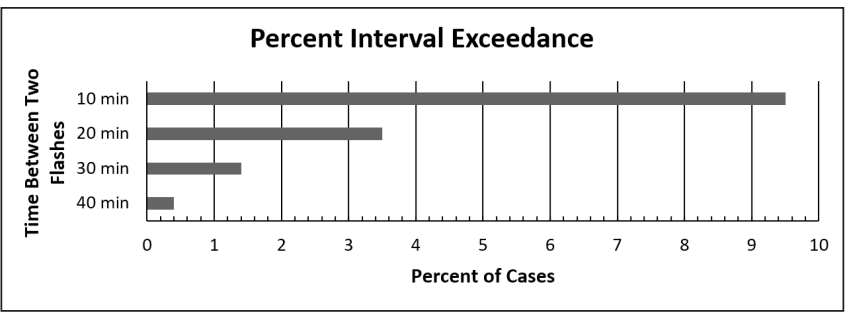

Figure 3. The total percentage of time intervals that exceeded 10, 20, 30, and $40 \mathrm{~min}$ for approximately 7.4 million inter-flash times of 1-45 min.

5) a large flash was observed extending well into the stratiform region behind the main line from Bryan to Waco to Tyler, Texas. In addition, ENTLN identified several separate cloud-to-ground strikes with this flash. This example shows the relevance and importance of being able to access the spatial-extent information that the GLM provides. As GLM observes the light emitted by the flash in $2 \mathrm{~ms}$ increments, numerous GLM events can occur in the same pixel. Over the course of the life cycle of a lightning flash of several seconds (world record of 7.74 s; Lang et al. 2017), more GLM events are likely to be observed in the main lightning channel. This allows for a generalized sense of the location of the lightning channel, particularly in regions with one or a couple flashes, such as in the stratiform region. Note in Fig. 5, the GLM shows a region of higher GLM event densities ( $\sim 100$ per grid box per minute; green) extending from Bryan to Tyler, Texas. Investigating this $1 \mathrm{~min}$ of data in $2 \mathrm{~s}$ intervals indicates that the majority of these events occurred within a single $2 \mathrm{~s}$ time frame, especially around Tyler, Texas. This suggests the likelihood of a contiguous flash extending towards Tyler, Texas. The length of this flash is well within the known verified length of lightning flashes (Lang et al. 2017).

The ENTLN observations show several cloud-toground strikes (yellow dots) that extend towards and around Tyler, Texas. These ENTLN observations all occurred within $0.96 \mathrm{~s}$ of each other and $\sim \mathrm{s}$ of the GLM observations. The temporal and spatial co-location of the ENTLN and GLM observations (particularly by Tyler, Texas) suggest that they are all part of a single flash. The ENTLN data provided some insight for the extent of the flash, and the GLM observations allow an end user to "connect the dots" and identify that these distinct cloud-to-ground observations were associated with the GLM observations and were likely part of the same flash. Even if the observations are part of more than one flash, from the end-user perspective of the 1 min of data in Fig. 5, there is observed lightning wellremoved from the main convective core with observed cloud-to-ground observations around Tyler, Texas, and the threat from lightning is imminent.

By retaining $30 \mathrm{~min}$ of data, a "large" flash will remain visible on the display to alert users of where lightning has been recently active. This is especially important in lower flash-rate situations. Figure 6 demonstrates this importance in a thundersnow event from March 2018. The GLM stoplight identified at least four separate flashes over New Jersey during the $30 \mathrm{~min}$ from 1743 through 1812 UTC. The spatial information allows end users to see trends in flash activity and interpret where active charging is located in the cloud. In this case, it also would indicate where the highest snowfall rates were possible given the strong spatial correspondence between lightning and heavy snow (e.g., Crowe et al. 2006; Pettegrew et al. 2009; Kumjian and Deierling 2015; Schultz et al. 2018). For completeness, further analysis demonstrated that there were actually four separate, large flashes. These are presented in the bottom half of Fig. 6 .

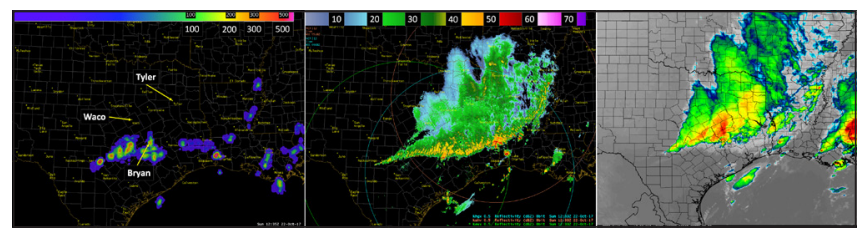

Figure 4. Geostationary Lightning Mapper event density plots (number of events per $10 \mathrm{~km} 2$, interpolated display) at 1235 UTC (left) and the corresponding radar reflectivity at $1233 \mathrm{UTC}$ (center) and ABI $10.3 \mu \mathrm{m}$ infrared at 1232 UTC (right) on 22 October 2017.

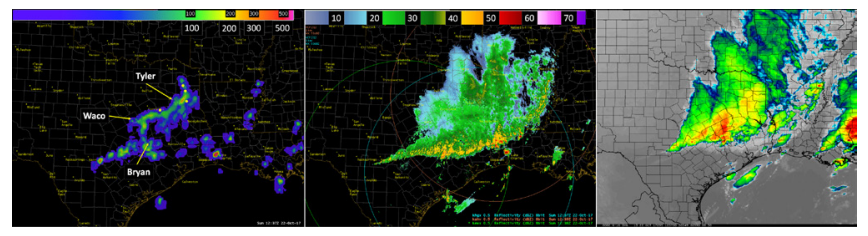

Figure 5. Same as Fig. 4 but at 1237 UTC for the GLM event density (left), radar reflectivity (center), and ABI $10.3 \mu \mathrm{m}$ infrared (right) on 22 October 2017. The yellow circles overlaid on the GLM (left) correspond to the four cloud-to-ground observations by ENTLN associated with the large flash extending into the stratiform region back towards Tyler, TX. 


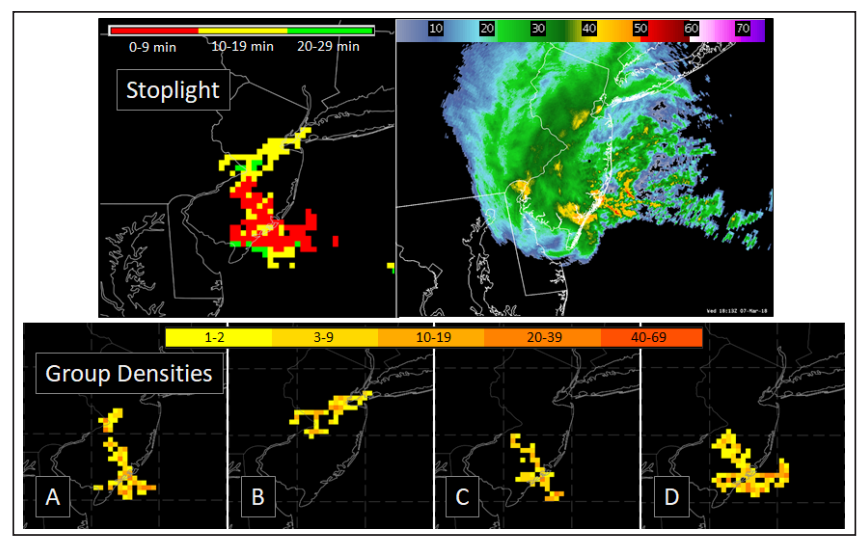

Figure 6. The GLM stoplight safety product (upper left) from the 7 March 2018 Nor'easter showing several large-spatial-extent lightning flashes during the thundersnow event across NJ from 1743-1812 UTC along with the radar reflectivity (upper right) at 1813 UTC. The four images below are the corresponding GLM group density observations (number of groups per $10 \mathrm{~km} 2$ ) at 1747 (A), 1800 (B), 1801 (C), and 1811 (D) UTC that show the four individual, large flashes that were observed in the stoplight product. (Note: For clarity only the four large flashes are shown.)

\section{c. GLM stoplight safety examples}

The GLM stoplight product will be formally evaluated with our EMA partners in the spring of 2019, but SPoRT is working with its collaborators to conduct an informal review to prepare basic training for this assessment. As such, an early example from 22 February 2018 covering $1 \mathrm{hr}$ starting at 1642 UTC and impacting MSFC is shown (Fig. 7a-1). Each figure shows the 1-min GLM group density, the GLM stoplight safety product, and radar reflectivity. A corresponding animation is available for this case.

This event begins at 1642 UTC on 22 February 2018 in northern Alabama (Fig. 7a-c). Storms are approaching from the west as shown by the radar reflectivity (Fig. 7c). The group density (Fig. 7a) and GLM stoplight (Fig. 7b) have an identical spatial footprint of 3 pixels. This represents lightning initiating for the first time in the area of interest. The group density has three separate colors, one for each pixel, representing (from north to south) 3-5, 40-49, and 1-2 groups over the course of $1 \mathrm{~min}$. The GLM stoplight, however, does not provide a density value but simply shows the extent of all lightning observed in the past 30 min. Because lightning has just initiated, all three pixels are red indicating that the observations are 0-9 min old.
Figure 7 (d-f) is the same domain, but now 25 min later at 1707 UTC. The radar shows that the storms have tracked eastward since 1642 UTC (Fig. 7f). Unlike the initiation at 1642 UTC, there are marked differences between the GLM group density (Fig. 7d) and GLM stoplight (Fig. 7e). The most recent GLM group display only illuminates two pixels in the past minute. With 30 min of data provided, the stoplight shows the spatial coverage of lightning in the past $30 \mathrm{~min}$. This visualization can be used to observe how lightning has progressed from west to east. Additionally, the stoplight safety product indicates that in the past $30 \mathrm{~min}$, no flashes have extended for more than a couple of $10-\mathrm{km}$ pixels. Therefore, the lightning has remained close to the main updraft and charging region. From MSFC's perspective, lightning is entering the outer action zone [32 km (20 miles) around the Center], but none is currently or recently observed within $16 \mathrm{~km}$ (10 miles). However, given the storm motion and recent nature of the lightning in the second cell, the inner action zone is likely to be impacted and a warning issued to evacuate MSFC workers indoors. Also of note, there are regions of red (0-9 min old) adjacent to green (2029 min old) pixels in the GLM stoplight. This illustrates how lightning can persist as a threat for a significant period, such as the $30 \mathrm{~min}$ used here. Lastly, the GLM stoplight safety product highlights two regions of active lightning.

Compared to the GLM stoplight product, the GLM density product indicates a measure of the intensity of the lightning with each frame. The GLM density product can provide similar spatial extent information as the stoplight product, but it requires viewing the data as an animation or accumulating the observations over a larger time period. The stoplight product provides the extent and location history in a single, succinct image. According to our EMA partners in a limited-data-access environment, which can occur at large outdoor venues or emergency sites (e.g., an overturned tanker), this ability to consolidate information into a single image is extremely valuable. Future versions will incorporate the GLM event data to address spatial extent more effectively than the GLM group data used in this iteration.

Stepping forward in time another $20 \mathrm{~min}$ to 1727 UTC, the group density (Fig. $7 \mathrm{~g}$ ) is indicating recent spatial extent but highlights only one active cell in the 1-min display. Taken in isolation, the density product indicates electrical activity on the north side of MSFC's $32-\mathrm{km}$ outer-action range ring. The single stoplight 
image at this time (Fig. 7h) indicates two storm cells of interest: the one to the north shown in the density product and another approaching from the west, which triggered the lightning warning in the inner action ring from Fig. 7e. Observations from this second cell indicate lightning has been recently active over MSFC and that the warning will remain in effect. Again, this information can be determined from the group density alone but requires animating the image (such as Figure 8 ) and keeping track of where lightning has been. The fact that the stoplight is showing red in this second cell also indicates that the cell is active and could still imminently produce another flash. Had the stoplight only shown green, this would indicate that the cell was most likely decaying.

At 1742 UTC, radar reflectivity continues to show several cells across the region (Fig. 71). The 1-min group density (Fig. 7j) does not show any current lightning. The stoplight product (Fig. 7k) shows lightning in three separate locations. The most active lightning remains on the northernmost storm and is moving generally to the east-northeast. The most recent lightning appears to be moving away from the MSFC $32 \mathrm{~km}$ range ring, although yellow and green observations are still present within this ring. This indicates that the northern storm is likely moving out of the area of concern, and no particularly large flashes were observed extending southwest in the past $30 \mathrm{~min}$. As a result, an all-clear may soon be warranted. The central storms show no lightning within the past 9 min (i.e., no red values in the stoplight). Should this trend persist and no new flashes are observed, the lightning warning initiated at 1707 UTC is likely to be dropped shortly. Lastly, a single, red stoplight pixel to the southwest highlights that lightning has initiated here within the last $10 \mathrm{~min}$, and that a new electrically active cell is possibly developing. This would require further monitoring in case it comes within range of MSFC, either directly or through large spatial extent flashes.

\section{Discussions}

\section{a. Inter-flash interval times relative to previous studies}

Stano et al. (2010) investigated the maximum inter-flash time intervals for 116 central Florida thunderstorms. Unlike this project, the Stano et al. (2010) work followed each storm individually. Here, we have taken an Eulerian approach and are observing time differences between two flashes at a given point.

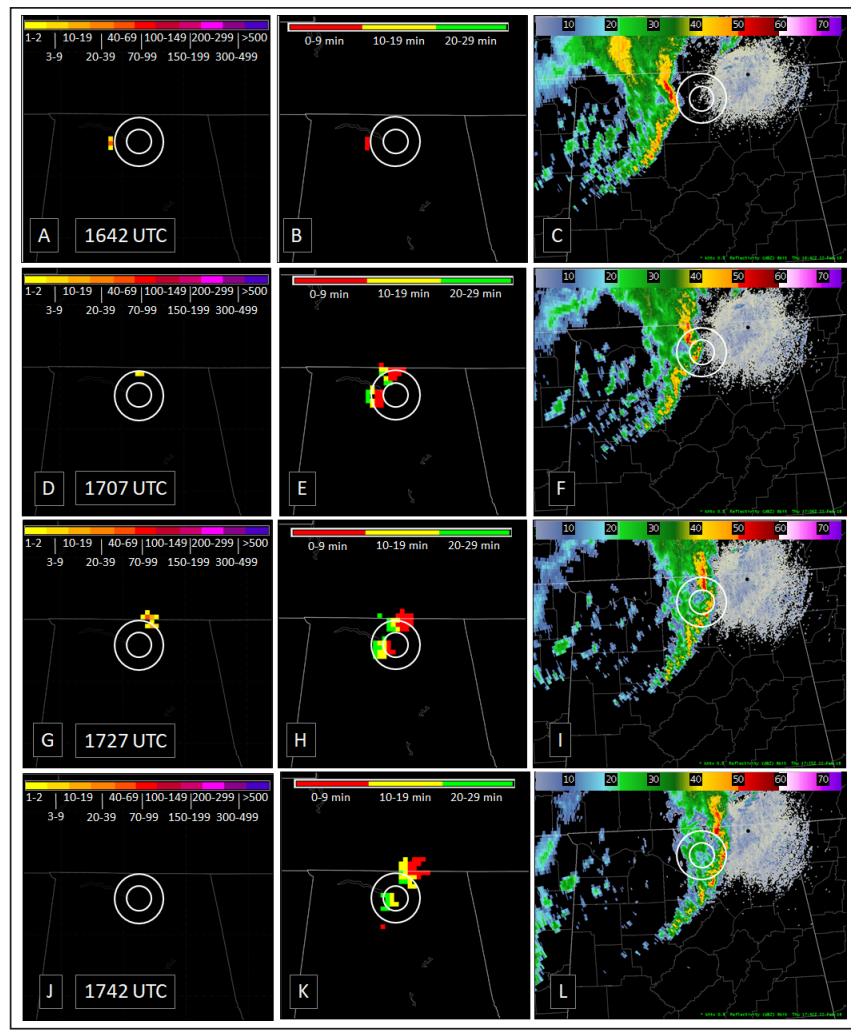

Figure 7. A sequence of lightning approaching the MSFC in Huntsville, AL on 22 February 2018. The white circles indicate $16-$ and-32 km $(\sim 10-$ and $\sim 20$ mile) radii around the MSFC and are used as the alert range for lightning. The rows correspond to 1642, 1707, 1727, and 1742 UTC. The individual images show the GLM group density (A, D, G, and J; number of groups per $10 \mathrm{~km} 2)$, GLM stoplight (B, E, H, and K; $10 \mathrm{~km} 2$ grid), and radar reflectivity (C, F, I, and L). Click image for animation.

As a result, this and the Stano et al. (2010) study cannot be explicitly compared one-to-one because the former study accounts for storm motion. We can discuss the similarities in the results but cannot infer that the similarities or differences are directly attributed to the same mechanics. Stano et al. (2010) had a median interflash time of $4.2 \mathrm{~min}$, a 75th percentile of $7.5 \mathrm{~min}$, a 95th percentile of $15 \mathrm{~min}$, and a 99.5 percentile of 25 min. The much larger GLM dataset, covering the full GLM field of view versus the Kennedy Space Center's Lightning Detection and Ranging network, does have two notable differences. The median through 75th percentile time differences are lower than those found by Stano et al. (2010) by 1.9 and 3.1 min, respectively. At the upper end, the GLM event-time differences are larger than those in Stano et al. (2010) by 1.1 and 8.5 
min for the 95th and 299 th percentiles. This likely indicates that the superior GLM coverage captures a far wider range of storms. Both analyses demonstrate that lightning activity can re-occur after significant periods of inactivity.

\section{b. GLM stoplight related to current lightning safety guidance}

The determination of when to return to outdoor activities will always be a balance between reducing downtime and making sure that the threat has ended. Ultimately, safety criteria are determined by the level of risk tolerance for a lightning threat. Even the longest temporal windows will likely have outliers and will not be non-zero. However, long wait times lead to excessive work stoppages. Future work will incorporate probabilistic statistics and real-time observations of thunderstorm characteristics to determine the probability of a lightning flash given current environmental conditions over a location so the end user can determine their level of tolerance to declare the lightning threat has ended for a specific location. This will evolve the product from a simple visualization to a more probabilistic tool.

\section{c. The utility of GLM stoplight and ground-based networks}

Ground networks make trade-offs depending on the role the network serves. LMAs, have extremely small (200-km radius) domains but are considered the most effective at detecting intra-cloud lightning and have been used extensively to validate GLM. Conversely, other ground networks can provide nearly global coverage, but these most reliably observe cloud-toground flashes (Cummins and Murphy 2009; Nag et al. 2015). These networks can observe a fraction of intracloud flashes, but often multiple intra-cloud flashes have been incorrectly assigned to the same lightning event (e.g., Schultz et al. 2017; 2018). Intercomparisons between ground-based networks like the NLDN or ENTLN and the satellite-based Tropical Rainfall Measurement Mission's Lightning Imaging Sensor (TRMM-LIS; Kummerow et al. 1998, Christian et al. 2003) demonstrated that the ground networks detect $27-46 \%$ of the same lightning events that TRMMLIS observed (e.g., Thompson et al. 2014; Bitzer and Burchfield 2016). Conversely, TRMM LIS observed $85 \%$ of the lightning events that ENTLN observed.
These differences are strongly influenced by the means with which each instrument observes lightning. The ground-based networks operate through magnetic detection finding through the very-low to very-high frequencies ( $\mathrm{Hz}$ to tens of $\mathrm{GHz}$ ). However, the GLM and TRMM-LIS operate through observations of visible light emitted by lightning from cloud tops. Inherently, each observation technique observes lightning at a different point within the life cycle of a lightning flash. This indicates that, although it is important to intercompare the different lightning observation instruments and networks, by their very nature there will never be a direct one-to-one agreement between each.

These observational differences affect the roles that ground networks and the GLM play in lightning safety. It is well-established that the ability to observe intra-cloud flashes as well as spatial extent is critical for lightning safety (Buechler et al. 2009; Stano et al. 2010; MacGorman et al. 2011; Holle et al. 2016; Schultz et al. 2017). This is where the GLM stoplight has its greatest strength as it incorporates GLM's ability to detect total lightning and the spatial extent of flashes. However, although GLM does observe both intra-cloud and cloud-to-ground flashes, it is incapable of specifically distinguishing which flash is which (Koshak and Solakiewicz 2015). This is where the ground networks (e.g., NLDN and ENTLN) are most beneficial. Therefore, combining the GLM stoplight with a ground-based network offers the strengths of each system by providing the spatial information of lightning along with the precision of where a cloud-to-ground flash came to ground. This reinforces what was stated in section 3b (Fig. 6) in that the GLM observations can "connect the dots" between multiple, disparate cloudto-ground observations.

\section{d. Early feedback from community partners}

From the local EMA and NWS perspective, the GLM stoplight lightning safety product has helped with decision support. It has made it easier for these operational partners to identify when the last lightning flash affected an area and also to determine which direction the lightning is moving. Figure 7 is an example of how the MSFC EMA was affected by a developing line of storms on 22 February 2018. They found that they were able to use the GLM stoplight to help predict how quickly the storm was approaching to know when they might have to issue an advisory. They 
also found the coloring and time-integration useful to determine that the storm north of MSFC was not going to impact their operations. In addition to identifying lightning cessation, the GLM stoplight product also can be utilized to determine the future threat of lightning in an area once lightning initiates in a thunderstorm and movement is noticeable.

\section{Conclusions}

NASASPoRT's collaborations with local emergency managers, as well as the emergency operations center for the MFSC, have focused on capabilities to utilize the GLM observations for lightning safety. The emphasis is on developing a real-time product that will:

1) quickly identify where lightning is currently located and where it has been over the past $30 \mathrm{~min}$;

2) show how long it has been since the last lightning observations;

3) incorporate multiple datasets (e.g., lightning, radar, satellite, roads, and political boundaries);

4) be easily available on mobile devices.

With these general guidelines, NASA SPoRT has developed the GLM stoplight safety product for use in lightning-safety applications with a prototype of the items above shown in Fig. 2. This was first tested with a sample of $80 \mathrm{~h}$ of GLM observations (Table 1) from the GLM calibration field campaign. Of 218 million pairs of GLM event-time differences, 7.4 million event pairs (i.e., inter-flash times) in GLM pixels had a time difference between 1-45 min. This has been provided to the end users as part of a quick look and web-mapping server internet display. As part of the preparations for assessing this product, several brief analyses were made. They are summarized here.

1) The GLM stoplight safety product, which maintains a display of lightning for $30 \mathrm{~min}$, is based on the guidance that states that individuals should remain indoors for $30 \mathrm{~min}$ after the last lightning flash is seen or thunder is heard.

2) Placing those pairs in the context of current lightning-safety metrics of how long to wait since the last flash for commercial airlines $(10 \mathrm{~min})$,
USAF (20 $\mathrm{min}$ ), and EMA/NWS (30 $\mathrm{min})$, this study observed that the temporal criteria were violated $9.5 \%, 3.5 \%$, and $1.4 \%$ of the time, respectively, in this 80 -h sample of GLM data. A further $0.4 \%$ of the cases had a time interval exceeding $40 \mathrm{~min}$. A key result is that a non-zero chance for lightning after $30 \mathrm{~min}$ does exist.

3) Because GLM does not discriminate cloud flashes from ground flashes, it is suggested that the GLM stoplight safety product be used in conjunction with ground-based, lightning-location sensors to maximize the safety potential for all end users who need lightning safety decision support. This combination of data utilizes the strengths of the space- and ground-based lightning observations.

4) Another key aspect of the stoplight product is that it can show spatial extent as opposed to the point locations of ENTLN or NLDN.

Future work includes the testing of the GLM stoplight safety product by end users during the latter half of 2018 (informally) and a formal assessment in the spring of 2019. This effort will assess the utility of this product and identify cases for training. The training cases will be used to prepare other local emergency managers as the project expands in the next year. Future work also involves the spatial characterization of the GLM relative to different warning range rings (e.g., Holle et al. 2016; Schultz et al. 2017) and probabilistic guidance to improve real-time, lightning-cessation guidance to end users. We will investigate updates to the display to better match recent updates to the GLM visualizations being implemented by NOAA. This places the GLM data onto the Advanced Baseline Imager's (ABI's) $2 \times 2$ $\mathrm{km}$ fixed grid from GOES (Bruning et al. submitted). The spatial grid change's impact will be minimal as the method downscales the native GLM pixel to $2 \mathrm{~km}$. Lastly, we are presently exploring machine learning techniques to add information to improve the concept beyond a binary yes/no answer.

Acknowledgments: The authors would like to thank the MFSC Emergency Operations Center, the local emergency managers in Bedford, Coffee, and Hamilton Counties, Tennessee, and the local forecast offices in Huntsville, Alabama, and Morristown and Nashville, Tennessee, for their collaborations and feedback. These collaborations have led to the product described here, 
and their time will be valuable in further evaluating the stoplight product this fall. This work was funded by the Office of the Chief Technologist at MSFC and NASA's Weather Focus Area led by Dr. Tsengdar Lee.

\section{REFERENCES}

Berndt, E., A. Molthan, W. W. Vaughan, and K. Fuell, 2017: Transforming satellite data into weather forecasts. Eos, 98, CrossRef.

Bitzer, P. M., and J. C. Burchfield, 2016: Bayesian techniques to analyze and merge lightning locating system data. Geophys. Res. Lett., 43, 12,605-12,613, CrossRef. , 2017: Global distribution and properties of continuing current in lightning. J. Geophys. Res. Atmos., 122, 10331041, CrossRef.

Bringi, V. N., K. Knupp, A. Detwiler, L. Liu, I. J. Caylor, and R. A. Black, 1997: Evolution of a Florida thunderstorm during the Convection and Precipitation/ Electrification Experiment: The case of 9 August 1991. Mon. Wea. Rev., 125, 2131-2160, CrossRef.

Bruning, E. C., and Coauthors (submitted): Meteorological imagery for the Geostationary Lightning Mapper. Submitted to J. Geophys. Res. Atmos.

Buechler, D. E., R. J. Blakeslee, and G. T. Stano, 2009: The North Alabama lightning warning product. Recorded Presentation 4th Conf. on the Meteorological Applications of Lightning Data. Amer. Meteor. Soc., Phoenix, AZ, 6.5. [Available online at ams.confex.com/ ams/89annual/webprogram/4ELECTRICATMOS.html.]

Cherington, M., J. Walker, M. Boyson, R. Glancy, H. Hedegaard, and S. Clark, 1999: Closing the gap on the actual numbers of lightning casualties and deaths. Preprints, 11th Conf. on Applied Climatology, Dallas, TX, Amer. Meteor. Soc., 10.4, 379-380.

Christian, H. J., 2006: Geostationary Lightning Mapper (GLM). 12th Conf. on Aviation Range and Aerospace Meteorology/2nd Conf. on Meteorological Applications of Lightning Data, Amer. Meteor. Soc., Atlanta, GA, $\mathrm{J} 2.3$.

, and S. J. Goodman, 1987: Optical observations of lightning from a high-altitude airplane. J. Atmos. Oceanic Technol. 4, 701-711, CrossRef.

, R. J. Blakeslee, and S. J. Goodman, 1992: Lightning Imaging Sensor (LIS) for the Earth Observing System. NASA Technical Memorandum 4350, NASA, Washington, D. C. [Available online at ntrs.nasa.gov/ archive/nasa/casi.ntrs.nasa.gov/19920010794.pdf.]
, and Coauthors, 2003: Global frequency and distribution of lightning as observed from space by the Optical Transient Detector. J. Geophys. Res., 108, ACL 4-1ACL 4-15, CrossRef.

Cooper, M. A., and R. L. Holle, 2012: Lightning safety campaigns_-USA experience. Preprints, 31st Int. Conf. on Lightning Protection, Vienna, Austria, IEEE, 1-8, CrossRef.

Crowe, C., P. Market, B. Pettegrew, C. Melick, and J. Podzimek, 2006: An investigation of thundersnow and deep snow accumulations. Geophys. Res. Lett., 33, L24812 (4 pp), CrossRef.

Cummins, K. L., and M. J. Murphy, 2009: An overview of lightning locating systems: History, techniques, and data uses, with an in-depth look at the U. S. NLDN. IEEE Trans. Electromagn. Compat., 51, 499-518, CrossRef.

Curran, E. B., R. L. Holle, and R. E. López, 2000: Lightning casualties and damages in the United States from 1959 to 1994. J. Climate, 13, 3448-3464, CrossRef.

Darden, C., B. Carroll, S. Goodman, G. Jedlovec, and B. Lapenta, 2002: Bridging the gap between research and operations in the National Weather Service: Collaborative activities among the Huntsville meteorological community. NOAA Technical Memorandum NWS SR-222, NWS Southern Region, Fort Worth, TX, 29 pp. [Available online at repository.library.noaa.gov/ view/noaa/6483.]

Dye, J. E., and Coauthors, 1986: Early electrification and precipitation development in a small, isolated Montana cumulonimbus, J. Geophys. Res. Atmos., 91, 1231-1247, CrossRef.

Goodman, S. J, F. P. Padula, and A. J. Pearlman, 2017: A post launch field campaign for GOES-R. Recorded presentation, 13th Symposium on New Generation Operational Environmental Satellite Systems, Amer. Meteor. Soc., Seattle, WA, 10.3. [Available online at ams.confex.com/ams/97Annual/videogateway.cgi/d/ 37498? recordingid $=37498$ \& uniqueid $=$ Paper302765\& entry password $=904462$.

D. E. Buechler, P. D. Wright, and W. D. Rust, 1988: Lightning and precipitation history of a microburstproducing storm. Geophys. Res. Lett., 15, 1185-1188, CrossRef.

, W. M. Lapenta, G. J. Jedlovec, J. C. Dodge, and T. Bradshaw, 2004: The NASA Short-term Prediction Research and Transition (SPoRT) Center: A collaborative model for accelerating research into operations. 20th Conf. on Interactive Information Processing Systems (IIPS) for Meteorology, Oceanography, and Hydrology, Amer. Meteor. Soc., Seattle, WA, P1.34, [Available online at ams.confex.com/ams/pdfpapers/73535.pdf.] , and Coauthors, 2013: The GOES-R Geostationary Lightning Mapper (GLM), Atmos. Res., 125-126, 34-49, CrossRef. 
Holden, N., O. Nava, C. Lewis, and W. P. Roeder, 2018: Forecasting lightning cessation using dual-polarization radar and lightning mapping array near Washington D. C. 7th Intl. Lightning Meteorology Conf., Ft. Lauderdale, FL, 8 pp. [Available online at www.vaisala.com/sites/ default/files/documents/Forecasting\%20Lightning\%20 Cessation \%20Using\%20Dual-Polarization $\% 20$ Radar\%20and\%20Lightning\%20Mapping\%20 Array $\% 20$ N.\%20Holden $\% 20$ et $\% 20$ al.pdf.]

Holle, R. L., 2012: Recent studies of lightning safety and demographics. Preprints, 31st Int. Conf. on Lightning Protection, Vienna, Austria, IEEE, 1-14, CrossRef. , 2016a: A summary of recent national-scale lightning fatality studies. Wea. Climate Soc., 8, 35-42, CrossRef. , 2016b: The number of documented global lightning fatalities. Preprints, 6th Int. Lightning Meteorology Conf., San Diego, CA, Vaisala, 4 pp. [Available online at my.vaisala.net/Vaisala\%20Documents/Scientific $\% 20$ papers/2016\%20ILDC $\% 20$ ILMC/Ron $\% 20$ Holle. $\% 20$ Number $\% 20$ of $\% 20$ Documented $\% 20$ Global $\% 20$ Lightning\%20Fatalities.pdf.]

, R. E. López, and B. C. Navarro, 2005: Deaths, injuries, and damages from lightning in the United States in the 1890s in comparison with the 1990s. J. Appl. Meteor., 44, 1563-1573, CrossRef.

, N. W. S. Demetriades, and A. Nag, 2016: Objective airport warnings over small areas using NLDN cloud and cloud-to-ground lightning data. Wea. Forecasting, 31, 1061-1069, CrossRef.

Jedlovec, G., 2013: Transitioning research satellite data to the operational weather community: The SPoRT paradigm. IEEE Geoscience and Remote Sensing Magazine, 1, no. 1, 62-66, CrossRef.

Jensenius, J. S., 2014: A detailed analysis of recent lightning deaths in the United States. Preprints, 5th Int. Lightning Meteorology Conf., Tucson, AZ, Vaisala, 8 pp. [Available online at www.vaisala.com/sites/default/files/documents/ Jensenius-A Detailed Analysis of Recent Lightning Deaths in the United States-2014-ILDC-ILMC.pdf.] , 2019: A detailed analysis of lightning deaths in the United States from 2006 through 2018. [Available online at www.weather.gov/media/safety/Analysis06-18.pdf.] , and D. B. Franklin, 2014: NOAA's efforts to reduce lightning fatalities through public education and awareness. Preprints, 5th Int. Lightning Meteorology Conf., Tucson, AZ, Vaisala, 5 pp. [Available online at www.vaisala.com/sites/default/files/documents/ Jensenius and Franklin-NOAA's Efforts to Reduce Lightning Fatalities through Public Education and Awareness-2014-ILDC-ILMC.pdf.]

Koshak, W. J., and R. J. Solakiewicz, 2015: A method for retrieving the ground flash fraction and flash time from satellite lightning mapper observations. J. Atmos. Oceanic Technol., 32, 79-96, CrossRef.
Kumjian, M. R., and W. Deierling, 2015: Analysis of thundersnow storms over Northern Colorado. Wea. Forecasting, 30, 1469-1490, CrossRef.

Kummerow, C., W. Barnes, T. Kozu, J. Shiue, and J. Simpson, 1998. The Tropical Rainfall Measuring Mission (TRMM) sensor package. J. Atmos. Oceanic Technol., 15, 809-817, CrossRef.

Lang, T. J., and Coauthors, 2017: WMO world record lightning extremes: Longest reported flash distance and longest reported flash duration. Bull. Amer. Meteor. Soc., 98, 1153-1168, CrossRef.

López, R. E., and R. L. Holle, 1998: Changes in the number of lightning deaths in the United States during the twentieth century. J. Climate, 11, 2070-2077, CrossRef. , R. L. Holle, T. A. Heitkamp, M. Boyson, M. Cherington, and K. Langford, 1993: The underreporting of lightning injuries and deaths in Colorado. Bull. Amer. Meteor. Soc., 74, 2171-2178, CrossRef.

MacGorman, D. R., I. R. Apostolakopoulos, N. R. Lund, N. W. S. Demetriades, M. J. Murphy, and P. R. Krehbiel, 2011: The timing of cloud-to-ground lightning relative to total lightning activity. Mon. Wea. Rev., 139, 38713886, CrossRef.

Miller, R., and N. W. S. Demetriades, 2018: Moderated discussion. Ramp closures and lightning distances Creating policies for airport ramp closures. 7 th Int. Conf. on Lightning Meteorology. Ft. Lauderdale, FL, Vaisala, 12-15.

Mogil, H. M., M. Rush, and M. Kutka, 1977: LightningAn update. Preprints, 10th Conf. on Severe Local Storms, Omaha, NE, Amer. Meteor. Soc., 226-230.

Nag, A., M. J. Murphy, W. Schulz, and K. L. Cummins, 2015: Lightning locating systems: Insights on characteristics and validation techniques, Earth and Space Science, 2, 65-93, CrossRef.

NOAA, cited 2019: Lightning Safety Tips and Resources (www.weather.gov/safety/lightning).

Pettegrew, B. P., P. S. Market, R. A. Wolf, R. L. Holle, and N. W. S. Demetriades, 2009: A case study of severe winter convection in the Midwest. Wea. Forecasting, 24, 121-139, CrossRef.

Preston, A. D., and H. E. Fuelberg, 2015: Improving lightning cessation guidance using polarimetric radar data. Wea. Forecasting, 30, 308-328, CrossRef.

Rison, W., R. J. Thomas, P. R. Krehbiel, T. Hamlin, and J. Harlin, 1999: A GPS-based three-dimensional lightning mapping system: Initial observations in central New Mexico. Geophys. Res. Lett., 26, 3573-3576, CrossRef. 
Rudlosky, S. D., S. J. Goodman, W. J. Koshak, R. J. Blakeslee, D. E. Buechler, D. M. Mach, and M. Bateman, 2017: Characterizing the GOES-R (GOES-16) Geostationary Lightning Mapper (GLM) on-orbit performance. Proceedings, 2017 IEEE International Geoscience and Remote Sensing Symposium, Fort Worth, TX, Institute of Electrical and Electronics Engineers, 279-282, CrossRef.

Schultz, E. V., G. T. Stano, L. D. Carey, and W. A. Petersen, 2013: Radar applications for nowcasting lightning cessation. Recorded presentation, Sixth Conf. on the Meteorological Applications of Lightning Data, Austin, TX, Amer. Meteor. Soc., 5.2. [Available online at ams. confex.com/ams/93Annual/webprogram/Paper220563. $\underline{\text { html. }}$.]

Schultz, C. J., G. T. Stano, P. J. Meyer, B. C. Carcione, T. Barron, 2017: Lightning decision support using VHF total lightning mapping and NLDN cloud-to-ground data in North Alabama. J. Operational Meteor., 5, 134145, CrossRef.

, T. J. Lang, E. C. Bruning, K. M. Calhoun, S. Harkema, and N. Curtis, 2018: Characteristics of lightning within electrified snowfall events using lightning mapping arrays. J. Geophys. Res. Atmos., 123, 2347-2367, CrossRef.

Stano, G. T., H. E. Fuelberg, and W. P. Roeder, 2010: Developing empirical lightning cessation forecast guidance for the Cape Canaveral Air Force Station and Kennedy Space Center, J. Geophys. Res. Atmos., 115, $\underline{\text { CrossRef, }} 18 \mathrm{pp}$.

Thompson, K. B., M. G. Bateman, and L. D. Carey, 2014: A comparison of two ground-based lightning detection networks against the satellite-based Lightning Imaging Sensor (LIS). J. Atmos. and Oceanic Technol., 31, 21912205, CrossRef. 